\title{
Prevalence of integrons in Shigella sonnei from Brazil
}

\author{
Jun $\mathrm{Yu}^{1}$, Eliana Guedes Stehling ${ }^{2}$, Michelle Angelini ${ }^{3}$, Janaína Luisa Leite ${ }^{3}$, Fernanda Pace ${ }^{3}$, Sagar Jadhav ${ }^{1}$ \\ and Wanderley Dias da Silveira ${ }^{3}$
}

The Journal of Antibiotics (2010) 63, 607-609; doi:10.1038/ja.2010.85; published online 28 July 2010

Keywords: drug resistance; integrons; real-time PCR; Shigella

Diarrhea contributes to high morbidity and mortality rates in developing countries. Diarrhea from all causes is ranked as the fourth cause of death and the second cause of loss of years of productive life. ${ }^{1}$ Infection by Shigella spp. is characterized by a watery diarrhea that may progress to mucoid bloody diarrhea, also known as dysentery. Each year, over 163 million episodes of endemic shigellosis occur in DCs, whereas only 1.5 million occur in developed ones. ${ }^{1}$ The increasing number of travelers to DCs, which have become attractive tourist destinations, has also increased the number of diarrhea episodes among millions of persons who travel each year from industrialized countries to DCs. ${ }^{2}$

Shigella dysenteriae and Shigella flexneri are the predominant species in tropical areas, whereas Shigella sonnei is predominantly isolated in industrialized countries. Although the disease is often self-limiting, effective antimicrobial therapy reduces the duration and severity of the dysentery and can also prevent potentially lethal complications. Concomitantly, the excretion of the pathogen in stools is shortened significantly by antibiotic therapy, reducing the spread of infection. ${ }^{3}$

New research suggests that gene cassettes and integrons may be one mechanism involved in transmission of multidrug resistance genes in many Gram negative bacteria. ${ }^{4,5}$ In Shigella spp., the dissemination of resistance-inducing genes is mostly facilitated by the ability of the bacteria to acquire transposons or plasmids that might contain integrons and DNA sequences that consist of two conserved segments (5'-CS and $3^{\prime}$-CS) separated by a variable region that usually comprises one or more gene cassettes. The $5^{\prime}$-CS region contains the integrase gene (intI), the integration site and a promoter region that allows expression of any number of gene cassettes inserted at the integration site site in a suitable orientation. The $3^{\prime}$-CS region usually comprises qacE $\Delta 1$ (encoding resistance to quaternary ammonium compounds), sul (resistance to sulfonamides), followed by ORF5 (of unknown function) and/or tni genes (transposition functions). ${ }^{6}$ Detailed studies have been conducted on three main classes of integrons, namely integron 1 (Int1), integron 2 (Int2) and integron 3 (Int3), each one characterised by the presence of a distinct and specific intI. ${ }^{7}$

In the present study, 25 different strains of S. sonnei, obtained from sporadic cases of shigellosis, were isolated in hospitals from Brazil's south eastern district of São Paulo (Campinas region), from six different Brazilian cities namely Campinas, Bragança Paulista, Vinhedo, Mogi Guacu, Limeria and Cosmopolis from 1997 to $2002^{8}$ (Table 1). The research aim is to investigate whether the resistance for two or more antibiotics encountered in these strains is associated with the presence of Int 1 , Int 2 and Int 3 .

The strains were tested with seven antibiotics (chloramphenicol, trimethoprim-sulfamethoxazole, streptomycin, sulfamethoxazole (SUT), cephalothin, ampicillin and tetracycline (TT)) to determine the antibiotic resistance profile of each strain according to the Manual of the Clinical and Laboratory Standards Institute. ${ }^{9}$

For the cell DNA extraction, only the bacterial colonies of virulent strains of Shigella were selected for analysis, on the basis of the uptake of Congo red from growth media. DNA was extracted according to the Spin Column Protocol (DNeasy Blood and Tissue Hand Book, Qiagen, USA, 2006) using the DNeasy Blood and Tissue Kit (Qiagen, Valencia, CA, USA, 2006).

The primers specific to Int1 (5'-ATGCCCGTTCCATACAGAAG- $3^{\prime}$ / $5^{\prime}$-CGGCCTTGCTGTTCTTCTAC-3'), Int2 (5'-AATGCGTTGCACTT CATTTG-3' ${ }^{\prime} 5^{\prime}$-ATGGGCAGTGAAGAGGTCAG-3') and Int3 (5'-CCG GTTCAGTCTTTCCTCAA-3'/5'-GAGGCGTGTATCTGCCTCAT-3') were designed using Primer3 software (http://frodo.wi.mit.edu/). The National Center for Biotechnology Information database (http:// www.ncbi.nlm.nih.gov/nuccore/) for Int1, Int2 and Int3 are, respectively, Locus FJ501977.1, Locus EF560799.1 and Locus AY219651.1.

The sequences obtained were used to design the primers, for which real-time PCR analysis was carried out on the samples for the amplification of the genes Int1, Int2 and Int 3 and was on the basis of the work of Maguire et al. ${ }^{10}$ with a few adaptations. The DNA from PCR was purified using a DNA purification kit (Qiagen, USA, 2006) and later it was sent for sequencing at MWG (Eurofins MWG operon, www.operon.com) to verify and confirm the presence of Int 1 , Int2 and Int3.

The amplification signals for Int 1 were registered between cycles 20-25 and showed a clear consistent signal until the 50th cycle for all strains except strains CS7 and CS16C, which failed to register any

${ }^{1}$ Strathclyde Institute of Pharmacy and Biomedical Science, University of Strathclyde, Royal College, Glasgow, UK; ${ }^{2}$ Department of Toxicological and Bromatologic Clinical Analyses, Faculty of pharmaceutical Sciences of Ribeirão Preto, USP, Ribeirão Preto, São Paulo, Brasil and ${ }^{3}$ Department of Microbiology and Immunology, Institute of Biology, State University of Campinas-UNICAMP, Campinas, São Paulo, Brasil

Correspondence: Dr EG Stehling, Department of Toxicological and Bromatologic Clinical Analyses, Faculty of Pharmaceutical Sciences of Ribeirão Preto, USP, Ribeirão Preto, São Paulo, Brazil.

E-mail: elianags@fcfrp.usp.br or eliana.stehling@gmail.com

Received 3 March 2010; revised 2 June 2010; accepted 8 June 2010; published online 28 July 2010 
Table 1 Year of isolation, strain identification, strain number in the gel, city of isolation, age of patient, the presence of integron 1 , integron 2 and integron 3 , and the antibiotic resistance

\begin{tabular}{|c|c|c|c|c|c|c|c|c|}
\hline Isolation & Strain & $\begin{array}{l}\text { No. } \\
\text { in gel }\end{array}$ & City & Age & Int1 & Int2 & Int3 & $\begin{array}{l}\text { Antibiotic } \\
\text { resistance }\end{array}$ \\
\hline 06-99 & CS4 & 1 & Campinas & $10 y$ & + & + & - & SUT, TT \\
\hline 03-02 & $\mathrm{CS} 16 \mathrm{H}$ & 2 & Campinas & $42 y$ & + & + & - & SUT, TT \\
\hline 03-01 & CS12 & 3 & Campinas & $3 y$ & + & + & - & SUT, TT, ET \\
\hline 05-97 & CS2 & 4 & $\begin{array}{l}\text { Bragança } \\
\text { Paulista }\end{array}$ & $15 y$ & + & + & - & SUT, ET, AP \\
\hline 05-02 & CS20 & 5 & Campinas & $\mathrm{N}$ & + & + & - & SUT, TT \\
\hline 03-00 & CS5 & 6 & Campinas & $2 y$ & + & + & - & SUT, TT, AP \\
\hline 04-02 & CS19B & 7 & Vinhedo & $\mathrm{N}$ & + & + & - & SUT, TT \\
\hline 03-02 & $\mathrm{CS} 17$ & 8 & Campinas & $5 y$ & + & + & - & SUT, TT \\
\hline 05-00 & CS7 & 9 & Campinas & $87 \mathrm{y}$ & - & + & - & SUT, TT, ET \\
\hline 02-02 & CS16A & 10 & Campinas & $4 y$ & + & + & - & SUT, TT \\
\hline 02-02 & CS16C & 11 & Campinas & $5 y$ & - & + & - & SUT, TT \\
\hline 05-00 & CS6 & 12 & Campinas & $7 \mathrm{~m}$ & + & + & - & SUT, TT, ET \\
\hline 02-02 & CS16D & 13 & Campinas & $4 y$ & + & + & - & SUT, TT \\
\hline 02-02 & CS16B & 14 & Campinas & $3 y$ & + & + & - & SUT, TT \\
\hline 04-02 & CS19A & 15 & Vinhedo & $\mathrm{N}$ & + & + & - & SUT, TT \\
\hline 03-02 & CS18 & 16 & Campinas & $\mathrm{N}$ & + & + & - & SUT, TT \\
\hline 03-02 & CS16G & 17 & Campinas & $6 y$ & + & + & - & SUT, TT \\
\hline 06-00 & CS8 & 18 & Campinas & $2 y$ & + & + & - & SUT, TT, ET \\
\hline 03-01 & $\mathrm{CS} 11$ & 19 & Campinas & $3 y$ & + & + & - & SUT, TT \\
\hline 03-02 & CS16I & 20 & Campinas & $6 y$ & + & + & - & SUT, TT \\
\hline 02-97 & CS1 & 21 & Mogi Guaçu & $23 y$ & + & + & - & SUT, TT, ET \\
\hline $10-98$ & CS3 & 22 & Limeria & $11 \mathrm{y}$ & + & + & - & SUT, TT, ET \\
\hline 06-01 & CS14 & 23 & Campinas & $\mathrm{N}$ & + & + & - & SUT, TT \\
\hline 02-02 & CS16E & 24 & Campinas & $5 y$ & + & + & - & SUT, TT \\
\hline 01-01 & CS9 & 25 & Cosmópolis & $2 y$ & + & + & - & SUT, TT \\
\hline
\end{tabular}

Abbreviations: AP, ampicillin; ET, streptomycin; Int, integron; m, months; $\mathrm{N}$, not available; SUT, sulfamethoxazole; TT, tetracycline; $y$, years; +, present; -, absent (Penatti et al. ${ }^{8}$ ).

significant signal (not shown). The samples were run on agarose gel and the bands at $200 \mathrm{bp}$ were seen for all the samples except for CS7 and CS16C, confirming the result of the PCR and indicating the presence of Int1 in the remaining samples (Figure 1a, Table 1). For Int2 (Figure 1b, (Table 1), the amplification signals were registered between cycles $10-15$ for 22 samples and between cycles $25-30$ for 3 samples and showed consistent signals terminating between cycles 25-45 (not shown). For Int3, the amplification signals were registered between cycles 30-35 for all the samples and showed a consistent increase in the signals until the 45th cycle. On agarose gel, no band appeared consistently at $200 \mathrm{bp}$ for all strains. In this way, Int 1 was present in $23(92 \%)$ isolates, Int2 was detected in all (100\%) the samples whereas Int3 was not detected in the strains (Table 1). Four random strains from the sample (CS18, CS16I, CS11 and CS1) were sequenced to check the presence of Int 1 and Int 2 . The results of DNA sequences were positive and confirmed the presence of these integrons in the four strains.

The 25 strains were screened for antibiotic resistance to seven different antibiotics and all of them were resistant for both SUT and TT. In addition to SUT and TT, 6 strains (24\%) showed antibiotic resistance to streptomycin and two strains (8\%) showed resistance to ampicillin. All the strains remained 100\% susceptible to chloramphenicol, trimethoprim-sulfamethoxazole and cephalothin.

The S. sonnei strains in Campinas were resistant to only two antibiotics (SUT and TT) until 2000, when three strains (CS6, CS7
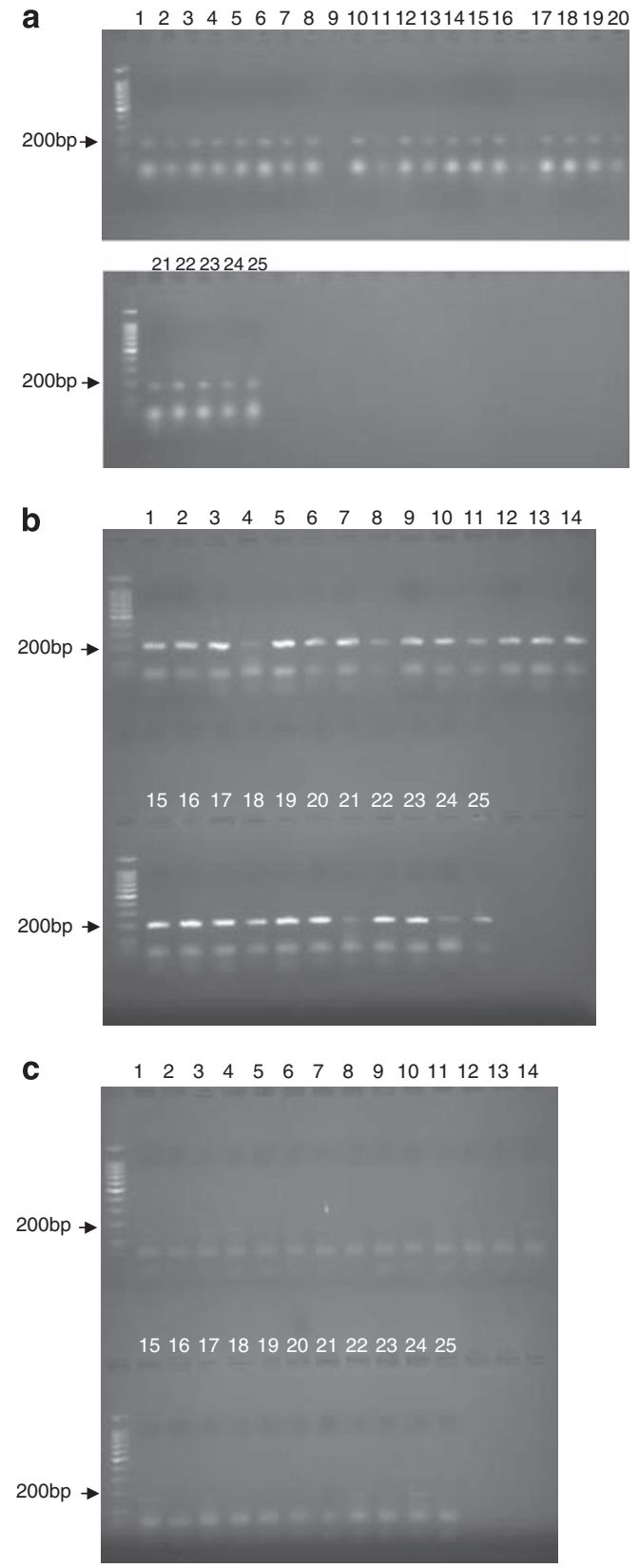

Figure 1 Agarose gel showing PCR samples for integron 1 (Int1), integron 2 (Int2) and integron 3 (Int3). (a) Int1 PCR samples. The samples are arranged and numbered as per Table 1 from first row to the second row. (b) Int2 PCR samples. The samples are arranged as per Table 1 from first row to the second row. (c) Int3 PCR samples. The samples are arranged as per Table 1 from first row to the second row.

and CS8) were found to also be resistant to streptomycin; another strain (CS5) was resistant to SUT, TTT and ampicillin. The first isolation of strains that showed resistance to three antibiotics occurred in Mogi Guacu and Braganca Paulista in 1997. All strains remained susceptible to chloramphenicol, trimethoprim-sulfamethoxazole and cephalothin.

In addition, S. sonnei strains isolated in São Paulo state showed the presence of at least two of the three integrons for which they were tested. Even if it is considered that the results for Int3 were inconclusive, $92 \%$ of the strains were positive for two integrons (Int1 and 
Int2) and all the strains showing resistance for two or more tested antibiotics had at least one of the integron. The detection rate of Int2 in Shigella in this study (100\%) was higher than in other reports, including the frequencies of $86.6 \%$ in other studies in $\mathrm{Brazil}^{3}$ and $76.9 \%$ in $\operatorname{Japan}^{11}$ and was similar to the frequency in Korea ${ }^{12}$ and Italy. ${ }^{13}$ However, the frequency of Int1 in Shigella in this study (92\%) was higher than that of Brazil $(6.7 \%),{ }^{3}$ Korea $(14.9 \%)^{12}$ and Japan $(3.8 \%) .{ }^{11}$ Gene cassettes conferring resistance to some commonly used antibiotics in the past, such as TT and streptomycin, have been discovered and it is known that resistance genes for new antibiotics used to treat shigellosis have become part of a gene cassette. ${ }^{14}$ Many studies have directly linked the presence of integrons with dissemination of antibiotic resistance genes among the world microbial population, with the consequence that the presence of multiple genes or gene cassettes may cause even the newest effective antibiotics to become ineffective quickly. $7,12,15$

From the results obtained, it was possible to conclude that no linkage of drug resistance to specific integrons could be proven, but nearly all strains evaluated did contain Int 1 and Int2.

1 Kottlof, K. L. et al. Global burden of Shigella infections: implications for vaccine development and implementation of control strategies. Bull World Health Org. 77, 651-666 (1999).

2 Virk, A. Medical advice for international travelers. Mayo Clin. Proc. 76, 831-840 (2001).
3 Peirano, G., Agerso, Y., Aarestrup, F. M., dos Reis, E. M. F. \& dos Prazeres Rodrigues, D. Occurrence of integrons and antimicrobial resistance genes among Salmonella enterica from Brazil. J. Antimicrob. Chemother. 58, 305-309 (2006).

4 Gassama-Sow, A. et al. Class 2 Integron+-Associated Antibiotic Resistance in Shigella sonnei isolates in Dakar, Senegal. Int. J. Antimicrob. Agents 27, 267-270 (2005).

5 Alekshun, M. N. \& Levy, S. B. Molecular mechanism of antimicrobial multidrug resistance. Cell 128, 1037-1050 (2007).

6 Rodríguez, I., Martín, M. C., Mendoza, M. \& Rodicio, M. R. Class 1 and class 2 integrons in non-prevalent serovars of Salmonella enterica: structure and association with transposons and plasmids. J. Antimicrob. Chemother. 58, 1124-1132 (2006).

7 Ploy, M. C., Denis, F., Courvalin, P. \& Lambert, T. Molecular characterization of integrons in Acinetobacter baumannii: description of hybrid class 2 integron. Antimicrob. Agents Chemother. 44, 2684-2688 (2000).

8 Penatti, M. P. et al. Epidemiological characterization of resistance and PCR typing of Shigella flexneri and Shigella sonnei strains isolated from bacillary dysentery cases in Southeast Brazil. Braz. J. Medical and Biol. Res. 40, 249-258 (2007).

9 Clinical and Laboratory Standards Institute. Performance Standards for Antimicrobial Susceptibility Testing. Sixteenth Information Supplement. M100-S1, CLSI: Wayne, PA, 2006.

10 Maguire, A. J., Brown, D. F. J., Gray, J. J. \& Desselberger, U. Rapid screening technique for class 1 integrons in Enterobacteriaceae and non-fermenting gram-negative bacteria and its use in molecular epidemiology. Antimicrob. Agents Chemother. 45, 1022-1029 (2001).

11 Ahmed, A. M., Furuta, K., Shimomura, K., Kasama, Y. \& Shimamoto, T. Genetic characterization of multidrug resistance in Shigella spp. from Japan. J. Med. Microbiol. 55, 1685-1691 (2006).

$12 \mathrm{Oh}, \mathrm{J}$. Y. et al. Changes in patterns of antimicrobial susceptibility and integron carriage among Shigella sonnei isolates from South-western Korea during epidemic periods. J. Clin. Microbiol. 41, 421-423 (2003).

13 Mammina, C., Aleo, A., Romani, C. \& Nastasi, A. Shigella sonnei biotype g carrying class 2 integrons in southern Italy: a retrospective typing study by pulsed field gel electrophoresis. BMC Infect. Dis. 6, 117 (2006).

14 Ve'ronique, D. et al. High genetic stability of integrons in clinical isolates of Shigella spp. of worldwide origin. Antimicrob. Agents Chemother. 51, 1333-1340 (2007).

15 Parsot, C. Shigella spp. and Escherichia coli pathogenicity factor. FEMS Microbiol. Letters 252, 11-18 (2005). 